\title{
Os indicadores de intersubjetividade e sua potência na clínica de crianças
}

\section{The intersubjectivity indicators and its potentiality in the children's clinic}

\section{Los indicadores de intersubjetividad y su potencia en la clinica de niños}

\author{
Vanessa Giaretta* \\ Universidade Federal do Rio Grande do Sul - UFRGS, Porto Alegre, Rio Grande do \\ Sul, Brasil \\ Milena da Rosa Silva** \\ Universidade Federal do Rio Grande do Sul - UFRGS, Porto Alegre, Rio Grande do \\ Sul, Brasil
}

\begin{abstract}
RESUMO
Os indicadores de intersubjetividade são uma espécie de guia, reunindo fenômenos que vêm sendo destacados pela literatura psicanalítica e indicam que a constituição psíquica da criança está se desenvolvendo no encontro com seu ambiente subjetivante. Tais fenômenos foram reunidos pelo psicanalista uruguaio Victor Guerra. Neste artigo, as autoras sustentam que esses indicadores podem se consolidar como uma ferramenta teórica e técnica na clínica de crianças que apresentam entraves em seu processo de subjetivação. É apresentado um resumo desses indicadores e cenas clínicas, visando compreender de que modo eles podem amparar o trabalho analítico, iluminando um caminho rumo à subjetivação.
\end{abstract}

Palavras-chave: intersubjetividade, subjetivação, psicanálise, clínica da infância.

\begin{abstract}
The intersubjectivity indicators are a kind of guide to countless phenomena that have been highlighted by psychoanalytic literature over the years, which indicates that the child is developing its psychic constitution by the encounter with its subjective environment. Such phenomena were collected and consistently arranged by the Uruguayan psychoanalyst Victor Guerra. In this article, the authors advocate the idea that these indicators can be consolidated as a theoretical and technical tool in the clinic of children that present obstacles in their process of subjectivation. Initially, a summary of these indicators is presented and then some clinical scenes are analised to comprehend how these indicators can support analytical work, illuminating a path towards subjectivation.
\end{abstract}

Keywords: intersubjectivity, subjectivation, psychoanalysis, childhood clinic. 


\begin{abstract}
RESUMEN
Los indicadores de intersubjetividad son una especie de guía acerca de innumerables fenómenos que vienen siendo destacado por la literatura psicoanalítica a los quales indican que la constitución psíquica del niño se está desarrollando en el encuentro con su ambiente subjetivante. Tales fenómenos fueron reunidos y arreglados de forma consistente por el psicoanalista uruguayo Victor Guerra. En este artículo las autoras sostienen que esos indicadores pueden consolidarse como una herramienta teórica y técnica en la clínica de niños que presentan obstáculos en su proceso de subjetivación. Se presenta un resumen de estos indicadores y se analisan algunas escenas clínicas para compreender de qué modo los indicadores pueden amparar el trabajo analítico, iluminando camino potente hacia la subjetivación.
\end{abstract}

Palabras clave: intersubjetividade, subjetivación, psicoanálisis, clínica de la infancia.

Os indicadores de intersubjetividade constituem uma espécie de guia que permitem analisar a qualidade da interação entre a criança e os cuidadores de referência, desde o nascimento até os dois anos (Guerra, 2009, 2014a, 2014b, 2014c). Esses indicadores dizem respeito a fenômenos cuja importância vem sendo destacada por diversos autores/pesquisadores vinculados à psicanálise e à psicologia do desenvolvimento ao longo dos últimos anos, e que foram reunidos e alinhavados de uma forma bastante rica pelo psicanalista uruguaio Victor Guerra. Eles formam "parte de uma estrutura primária do vínculo, base do que poderia ser a autonomia psíquica do bebê, a capacidade de brincar e simbolizar" (Guerra, 2017, p. 11).

É uma maneira autêntica e sensível que o autor propõe para conduzir nosso olhar sobre a estruturação emocional na infância, dando o devido lugar e importância a cada um dos fenômenos já desvendados, os quais indicam que o processo de subjetivação da criança está acontecendo. Neste artigo, pretendemos destacar como o conhecimento aprofundado desses indicadores pode iluminar nosso fazer na clínica da infância, ajudando a criar caminhos que facilitem a subjetivação, especialmente naquelas crianças que encontram entraves nesse processo.

Victor Guerra atuou fortemente no campo da infância, sobretudo com bebês de 0 a 3 anos, trazendo novos subsídios para a compreensão e a clínica dessas crianças. Guerra teve mais de 25 anos de experiências com consultas terapêuticas vinculares e observação pais-bebê, interrogando-se todos esses anos a respeito de como participa o outro na construção subjetiva da criança. Com base em sua experiência desenvolveu os indicadores de intersubjetividade (Guerra, 2014a, 2014b, 2014c).

Antes de apresentar um resumo desses indicadores, é fundamental esclarecer o que implica a noção de intersubjetividade. Foi a partir 
dos estudos de Daniel Stern (1980), no final da década de 70, e de Fraiberg, Adelson e Shapiro (1994), no início da década de 80, que o campo das relações mãe-bebê começou a evidenciar as potencialidades interativas do bebê, mesmo um recém nascido, dando início às ideias que fundamentam a Intersubjetividade. Nessa perspectiva, ambos envolvidos - cuidador-bebê - são coparticipantes ativos na criação de uma experiência emocional (Golse, 2013).

Para Victor Guerra, a intersubjetividade pode ser resumida como a língua universal dos seres humanos (Guerra, 2009). É um sistema partilhado que está na raiz da linguagem, amparando nossa comunicação: a expressão fina dos olhos, das sobrancelhas e da boca, as nuances da voz, os gestos, a movimentação e o tônus corporal muscular. Aspectos que, na experiência inicial do bebê com o outro, se tornam o primeiro plano da comunicação. O adulto cuidador inclusive inconscientemente amplia toda essa mímica expressiva, criando uma estrutura dialógica, em que os atos e sons que a pequena criança produz são tomados como discurso (Stern, 2004). Assim, pela via não verbal, mãe e bebê vão compartilhando vivências emocionais, as quais permitem que se construa o self e a maneira singular da criança sentir as experiências, isto é, sua subjetividade (Guerra, 2009).

É um encontro melódico, pois se conduz dentro de uma dança rítmica, em que preponderam as mensagens não verbais, de colorido afetivo, possibilitando que se crie uma linguagem própria da infância, a qual lança o bebê no espaço potencial, em que ele se sente participando de uma experiência comum, humana e coletiva. Assim, o cerne da intersubjetividade implica em "estar com", conhecer e fazer parte do universo do outro, agregar-se a ele e criar junto uma espécie de melodia comum (Stern, 2004).

Apresentamos a seguir um resumo desses indicadores de intersubjetividade, os quais Guerra desenvolveu em seus escritos com artesania e profundidade, fundamentando sua importância. Parte de uma indiferenciação e total dependência do bebê ao cuidador e vai rumando para uma discriminação cada vez maior dos estados mentais e emocionais próprios e dos outros (Guerra, 2009, 2014c). Ao lado do título do indicador, observa-se a referência cronológica, em meses, de quando, em média, se espera observar tal indicador:

1) Intercâmbio de Olhares (0-2 m):

O olhar é como uma porta de entrada, "um dos primeiros sinais de encontro afetivo entre as pessoas" (Guerra, 2014a, p.219). O grau de fascinação visual pelo cuidador indica a qualidade do apego, o desejo e a emoção estética por descobrir os mistérios que habitam o outro. O não olhar do bebê pode ser um indício de evitamento relacional, comumente presente na identificação precoce do autismo (Guerra, 2014c). 
2) Jogos Cara-a-Cara e as Protoconversaçoes (2m):

Os jogos cara a cara se estabelecem durante as trocas de olhar, e se constituem em uma variedade de gestos e expressões faciais que o adulto faz, geralmente acompanhado de sons, os quais vão sendo repetidos com pequenas variações, com a finalidade de atrair a atenção da criança (Stern, 1980). Nessas circunstâncias o bebê age e observa o efeito que produz sobre o outro (Guerra, 2009, 2014a). A protoconversação ocorre durante os jogos cara-a-cara, e diz respeito ao intercâmbio de sons entre a criança e o cuidador, com intencionalidade comunicativa. O bebê faz uma leitura da quantidade de palavras que o adulto Ihe dirige, do colorido e do volume de voz, mesmo que não entenda os significados da língua.

3) Papel da Imitação:

A capacidade de imitação está presente já no recém-nascido, e é uma forma precoce e provavelmente inata de estabelecer contato com o semelhante. Estaríamos desse modo orientados a preferir o rosto e a companhia humana, como meio de nos orientar e nos proteger do desamparo. $O$ ato de imitar significa tocar e alojar o outro dentro de si, introjetá-lo, permitindo posteriormente a separação. No princípio, a imitação estaria restrita à face, como abrir e fechar os olhos, a boca ou movimentar a língua, e aos poucos vai se ampliando e dando lugar aos jogos "como se", e a formação de uma teoria da mente (Guerra, 2009, 2014a, 2014c).

4) Jogos de Cosquinhas e suspense (Micro ritmos) (3-5m):

Essas são brincadeiras que os adultos geralmente propõem com as mãos, movimentando-as em consonância com uma música ou as utilizando ludicamente para ameaçar pegar ou fazer cosquinhas em uma parte do corpo do bebê. Envolvem uma gama de elementos rítmicos, que ajudam a marcar uma temporalidade. Inauguram o papel da surpresa na vida psíquica, ao mesmo tempo em que estão inseridos em uma estrutura contínua e previsível, que oferece segurança, tornando prazerosa a descontinuidade e o encontro com o novo (Guerra, 2009,2014a).

5) Vocativos Atencionais (5-12m):

Desde os 4 meses o bebê é capaz de compreender que um próximo evento irá acontecer em uma direção indicada. A atenção é dirigida até um objeto alheio, sem ser interrompida por outros estímulos sensoriais. Através de sons vocativos, carregados de emoção e ludicidade, a mãe busca captar o bebê e instigar seu desejo para algo que está além dela mesma. É o prólogo da atenção conjunta e do deslocamento motriz pelo espaço (Guerra, 2009, 2014a).

6) Olhar Referencial (Deslocamento no espaço) (5-8m):

Desde o momento em que o bebê pode sentar-se e engatinhar, isso modifica sua maneira de interagir e de ver o ambiente a sua volta. $O$ olhar referencial diz respeito à atitude do bebê de verificar no rosto do cuidador sua expressão frente a uma situação desconhecida, 
negociando seus movimentos e amparando-se na expressão de seu rosto para guiar suas reações. Indica se mãe/pai são usados como referência de adequação social e de um vínculo de segurança (Guerra, 2009,2014b, 2014c).

7) Atenção Conjunta - Objeto Tutor (6-9m):

Atenção conjunta é a competência que nós primatas temos de manifestar ao outro algo que está no centro do nosso interesse. Aqui está em jogo a capacidade do bebê em orientar sua atenção até um objeto com o qual seu cuidador interage, ingressando com ele em uma relação triádica (pessoa-pessoa-objeto). Sinaliza o rompimento de uma relação exclusivamente dual. Os cuidadores se utilizam de sons e vocativos carregados de emoção e ludicidade, que são como pontes que os ligam ao desejo da criança sobre os eventos e objetos. A seguir, tecem narrativas com a intenção de cativar emocionalmente a criança. Esse gesto tem a potência de comunicar ao bebê o prazer de descobrir o mundo e servir como um modelo de como orientar-se frente às novas experiências na companhia de seus semelhantes. (Guerra, 2009, 2014b, 2014c).

$\mathrm{O}$ bebê entretém-se com esses objetos, testemunhos do encontro afetivo com o outro cuidador, ficando sob sua tutela enquanto a mãe se ocupa de outra coisa. Os objetos tutores são, portanto, mediadores da separação da mãe e do bebê, podendo ser adotados como elementos familiares que carregam marcas e memórias cocompartilhadas. Ao mesmo tempo, esse jogo lúdico da mãe, que contorna de palavras e empresta vida a esses objetos do cotidiano, oferece para a criança capacidade de entrar no mundo imaginário e narrativo da brincadeira (Guerra, 2014, p. 35).

8) Jogos de Esconde e Acha (8m):

Esses jogos iniciam em uma etapa na qual os adultos intuitivamente começam a convocar o bebê para brincadeiras de esconde-esconde, tapando seu rostinho com um pano, enquanto fazem de conta que o procuram. Geralmente é acompanhada da narrativa rítmica "Cadê?" e "Achou!". O momento do encontro é permeado de olhares jubilosos e risadas com grande intensidade afetiva. Essa organização temporal da brincadeira dá segurança para o bebê suportara angústia da separação e assim elaborar de forma lúdica o temor que sente ao perder de vista a mãe ou cuidador (Guerra, 2009, 2014b, 2014c).

9) Sintonia Afetiva (9-12m):

É a experiência mútua de compartilhar um estado emocional. O bebê demonstra a intensidade afetiva com que vive um evento através de seus gestos e vocalizações, e nessas ocasiões a mãe compreende e responde na mesma magnitude, mas sem imitá-lo. O principal, portanto, é que as emissões maternas marcam e espelham no mesmo grau de intensidade o que a criança sente, mas por outro canal comunicativo, como pela palavra, por exemplo, numa experiência de transmodalidade. Essa dança de expressividades ajuda 
no processo de regulação emocional da criança (Guerra, 2009, 2013, 2014b, 2014c).

10) Interludicidade (8-12m):

A Interludicidade implica o prazer de estar com e jogar junto. A conquista desse indicador nos dá indício de uma expressiva transformação que se produziu no mundo interno da criança, e que por sua vez revoluciona a forma como ela se relaciona com os outros. As pessoas passam a ser percebidas como objetos mais inteiros, que interatuam no seu universo subjetivo. As experiências assumem novos sentidos, o mundo ao redor é entendido como algo a ser compartilhado com os outros. A iniciativa pelo desejo do encontro, e pelo prazer extraído desse encontro gera uma verdadeira eclosão na intersubjetividade (Guerra, 2014a, 2014b). Por diferentes perspectivas, a literatura aponta que há um avanço psíquico de extrema relevância nessa capacidade de fruição: a condição para estabelecer a atenção compartilhada, vivenciar a posição depressiva, experimentar a angústia da separação e alcançar o terceiro tempo do circuito pulsional são alguns fenômenos englobados neste indicador (Guerra, 2013).

11) Assinalamento Protodeclarativo (12m):

Antes o bebê podia seguir a direção do dedo de alguém e compartilhar o que atraia a atenção do outro. Aqui há um avanço: o bebê se torna o protagonista e é ele que direciona seu dedo até um evento de interesse para comprovar que o outro compartilha de suas descobertas e de sua atenção. "É como uma alternância de pontos de vista" (Guerra, 2009, p.40). Esse é um signo evidente da capacidade comunicativa do infante, a qual precede a emergência da linguagem verbal, do pensamento e da representação. Cabe frisar que esse gesto é diferente do assinalamento proto-imperativo, que reside em apontar como meio de obter algo que a criança não consegue alcançar sozinha. $O$ assinalamento protodeclarativo implica 0 compartilhar intersubjetivo, a aceitação do espaço entre eu e os outros (Guerra, 2009, 2014b, 2014c). Está na "base do que pode chegar a ser o prazer de pensar junto" (Guerra, 2014b, p.431).

12) Início da Marcha: dialética perto-longe (12-18m):

Este indicador está basicamente fundamentado nas observações de Mahler (1982) a respeito dos processos de separação e individuação, responsáveis pelo nascimento psicológico da criança. O início da marcha contribui sobremaneira para a aquisição do sentimento de um "eu". A partir do momento em que o bebê consegue assumir a posição ereta e movimentar-se verticalmente, isso inaugura uma nova percepção do mundo diante de seus olhos. A dialética pertolonge adquire um status especial entre ele e a mãe, pois ambos irão procurar ativamente encontrar uma distância ótima, que permita a continuidade do crescimento emocional (Guerra, 2009, 2014b).

13) Consciência Reflexiva (18m): 
"Aos 18 meses aparece essa consciência que pode ser considerada como o corolário das experiências repetidas de intersubjetividade" (Guerra, 2009, p.49). É um momento especialmente interessante, em que o bebê consegue compreender o sentimento das outras pessoas e inclusive envolver-se nesses afetos, consolando, cuidando, ajudando. Essa capacidade empática sinaliza e implica modificações importantes no self da criança, como as crises de raiva e o maior domínio do recurso verbal (Guerra, 2014b).

14) Jogos de Imitação Diferida (18-24m):

Após a habilidade de imitar um modelo imediatamente após sua ação, agora a criança já é capaz de usar a memória e reproduzir situações mais complexas, que não estão presentes no aqui-agora, mas que foram observadas tanto nas pessoas, como nos animais ou objetos. A imitação diferida configura-se, portanto, como a representação no nível da comunicação corporal, abrindo passagem para a representação simbólica ao nível da linguagem verbal, através da narrativa (Guerra, 2009).

15) Jogos "Como Se" (24m):

Guerra retoma a etimologia do termo "símbolo", provinda do grego: quando uma pessoa recebia um hóspede, na hora de sua partida, eles quebravam uma tabuleta e cada um devia conservar uma metade, como forma de reconhecimento do laço. O amuleto se tornaria então um vestígio que comprova uma história passada. Logo, ao mesmo tempo em que o símbolo prescinde de uma forma concreta, não é a coisa em si. Está permeado da metáfora, pois o processo de separação de sua ligação originária é acompanhado de um deslocamento: uma coisa que fica representada por outra. Está, portanto, em íntima relação com a percepção da falta, da separação, a exploração do mundo e uso da imaginação (Guerra, 2009, 2013). A aquisição da brincadeira simbólica indica assim o desenvolvimento dos processos de simbolização e metaforização, e "é um dos processos fundamentais por meio dos quais o ser humano se transforma em sujeito" (Guerra, 2013, p. 584).

16) Linguagem verbal ( $24 \mathrm{~m})$ :

As palavras são como tijolos que erguem o pensamento e permitem a simbolização. Elas que nos ligam e expressam o sentido da experiência rítmica da vida de unirmos e separarmo-nos de alguém. A linguagem verbal é, portanto, metáfora do elo, do encontro com nosso semelhante. Conforme Guerra (2009), para dominarmos a linguagem simbólica e usarmos as palavras como legenda da nossa vida psíquica, teremos antes que ter sido falados, nomeados, cantados, narrados, construídos pela boca de outrem. A voz, o verbo, é ponte que nos conduz até o outro. É porque essas pontes foram construídas que a criança pode se lançar nessa nova dimensão do espaço e ser sustentada pelas palavras que foram tecendo sua 
história. Esse indicador culmina assim na consolidação da capacidade simbólica e na aquisição de uma noção de "eu" (Guerra, 2009, 2013).

Conforme Guerra (2014a), é a partir dessas vivências partilhadas que a criança pequena estabelece seu self. Isto significa dizer que as trocas afetivas e essa comunicação co-construída permitem que o bebê vá se subjetivando, ou seja, sustentando-se no outro para gradativamente descobrir e expressar sua forma singular de sentir, perceber e estar no mundo. Essa crescente apropriação da sua perspectiva vai sendo comunicada através da sua gestualidade corporal, da sua ritmicidade e dos seus recursos simbólicos. Assim, aos poucos, seu mundo de sensações passa a ser um mundo de representações. Quanto mais amplos e flexíveis seus canais expressivos, mais rica sua vida psíquica (Guerra, 2009).

As psicopatologias graves da subjetivação comumente encontram suas raízes em um desencontro rítmico inicial com o ambiente intersubjetivo da criança. Em conformidade com essas ideias, Guerra (2015, 2016, 2017) propôs o conceito de Transtorno de Subjetivação Arcaica. Tal conceito se refere a uma falha na instauração desse ritmo necessário, levando a um desencontro que compromete o processo de subjetivação do bebê. Em uma relação comum de uma mãe com seu filho, há um jogo cíclico de desajustes e ajustes que visam reparar as falhas e os desencontros na interação (Marcelli, 2000), mas em alguns casos e por diferentes razões pode não haver espaço para a reparação, marcando desde muito cedo uma desarmonia interativa permeada por confusão, tensão e desprazer que pode ter sérias consequências, como o retraimento do bebê e também da mãe. Essas interações descompassadas acontecem muitas vezes na história de crianças diagnosticadas com autismo e psicose.

Nos últimos 10 anos, uma aparente epidemia do autismo parece ter se manifestado. No entanto, mesmo com muitas pesquisas aventando possíveis causas ambientais catalisadoras para o fenômeno, não é possível afirmar que a prevalência de fato tenha aumentado. Guerra (2004, 2015, 2016), assim como outros autores (Frances, 2013; Jerusalinsky, 2015; Kupfer, 2014), alerta para o excesso de diagnósticos na infância nos últimos anos, especialmente 0 Transtorno Afetivo Bipolar, o Transtorno de Déficit de Atenção e Hiperatividade e mais recentemente o Transtorno do Espectro do Autismo. Os referidos autores contestam como explicação a melhoria nas ferramentas diagnósticas, sobretudo porque acreditam que os critérios das doenças mentais se tornaram muito alargados com 0 DSM IV e o DSM-5, facilitando enquadrar crianças com qualquer risco psíquico dentro de um transtorno psiquiátrico como o TEA.

O psicanalista uruguaio assinala que, pela via da psicanálise, não podemos pensar apenas nos aspectos biológicos impactando 0 
desenvolvimento dos indivíduos, pois sabemos da extraordinária influência do inconsciente sobre as vicissitudes implicadas no processo de subjetivação. Comenta que tem se considerado a interferência dos fatores ambientais sobre essas epidemias, mas muitas vezes sem inserir neles o vértice dos vínculos e das relações do ambiente subjetivante e da cultura na qual a família da criança está inserida (Guerra, 2016).

Na experiência de Guerra (2016), alguns desses casos de suspeita de TEA revelam crianças com sintomas ambíguos, em que a capacidade simbólica está inoperante, mas apresentam, em contrapartida, algumas condições de interação que diferem dos casos típicos do autismo. Para ele, essas apresentações são mais condizentes com aspectos depressivos do bebê, que levam a um evitamento relacional, talvez em decorrência de um aparato constitucional hipersensível, e por dificuldades do ambiente em lidar com essa sensibilidade. 0 bebê, nesses casos, encontra uma subjetivação falida, em razão de uma disritmia que se instala no encontro com o adulto cuidador, levando a dificuldades nos processos de simbolização.

A partir desse momento, trazemos algumas cenas clínicas visando compreender de que modo entendemos que os indicadores de intersubjetividade podem se consolidar como um potente instrumento clínico, mesmo naquelas crianças que já ultrapassaram o período subjacente a uma intervenção precoce, ou seja, para além dos 3 anos de idade. Não iremos abordar aqui aspectos sintomatológicos ou diagnósticos dos pacientes, mas cabe pontuar que foram escolhidos casos que apresentavam significativas dificuldades em seu processo de subjetivação.

Esclarecemos, a partir das concepções de Ferrari (2011), que ao utilizarmos o relato clínico como método de estudo nesse artigo, deve-se considerar que a escrita do caso não corresponde à verdade dos acontecimentos, carregando consigo um caráter de ficção. Deste modo, as cenas clínicas utilizadas, produtos da memória e dos registros, são restos transferenciais que foram produzidos pela dupla paciente-terapeuta, os quais provocaram as reflexões do analista em um tempo posterior, o que não interfere no que já foi vivido. Visamos, portanto, compartilhar as implicações de um saber singular e maleável acreditando que ele pode servir de inspiração para o advento de um novo (Figueiredo, 2004).

\section{Dança da Subjetivação: Espelhando e Narrando um Universo de Percepções}

Em nossa cultura, o olhar representa a primeira porta para uma interação e para um contato emocional com alguém. Portanto, a qualidade do olhar indica muito sobre o que se passa no mundo 
interno do outro. É através do olhar que se inaugura o encontro do bebê com seu ambiente. Deste modo, observar na criança o grau de vitalidade, de interesse e de intensidade na interpenetração do olhar (primeiro indicador de intersubjetividade), ou então a sua recusa ou fragilidade, nos indica o tipo de apego e de vínculo que estabelece com seus cuidadores (Guerra 2009, 2014a).

No caso de K ( 7 anos), seu olhar era raso, pouco revelador. Recordo ${ }^{1}$ uma ocasião em que ele estava mais desorganizado na sessão e fez um desenho bastante confuso, com uma mistura de elementos bizarros. Em uma parte do desenho estava um olho desenhado e logo abaixo escrito "olho duro". Penso que essa era a representação arcaica que ele tinha sobre o encontro de olhares: os olhos como superfícies impenetráveis, pétreas, através dos quais não era possível mergulhar para dentro do universo e da mente do outro.

Percebi que precisava funcionar para K como um espelho, algo que comprovasse que tinha um corpo no espaço. Os passos do garoto eram sempre muito rápidos, sendo difícil acompanhá-lo, e tentei então buscar seu ritmo, espelhando os movimentos das pernas dele nas minhas. Pensando na importância da imitação (terceiro indicador de intersubjetividade) para o nascimento da subjetividade, 0 espelhamento feito pelo ambiente cuidador é uma experiência fundadora da imagem do eu, central para o processo de "construção do verdadeiro self e da regulação dos afetos" (Guerra, 2014b, p. 19). É como se, ao mimetizar os passos de $K$, eu validasse seu corpo, seu tempo, inscrevendo sua identidade rítmica. A comunicação inconsciente seria: "Há outro fora de mim e o gesto e emoção que saem de mim são recebidos por ti e não se perdem. Quando me são devolvidos, sinto que existo" (Guerra, 2014b, p. 19).

Também havia momentos em que a sessão se constituía apenas de uma narrativa que eu fazia sobre seus gestos. Como se fosse um bebê, narrava por onde passeavam seus olhos, seus dedos, esclarecia os sons que o assustavam durante os atendimentos, traduzindo seu universo perceptivo e estabelecendo com ele um "diálogo tônico", característico das protoconversações (segundo indicador de intersubjetividade). Ou seja, quando o adulto cuidador concebe a gestualidade do bebê como uma forma precoce de comunicação, atribuindo a ele ludicamente intenções, que são traduzidas com palavras (Guerra, 2014b, p.11). Compreendo que revivi esses episódios com K, mesmo que ele já não fosse há tempos um bebê:

K estava sentado à minha frente, olhava fixo para o plug da luz.

T: Hum, tu estás olhando o plug da tomada...

K: (Surpreso) Eu já disse que eu gosto de fazer isso!

$\mathrm{T}$ : Eu sei, por isso que reparei. Tu gostas também de olhar a luz... 
Ele mexe os dedos pela cadeira.

$\mathrm{T}$ : Agora teus dedos são patinadores...

K: O quê...? Eu brinco disso! (Surpreso)

T: Sim, eu sei, tu que gostas de imaginar que teus dedos são patinadores patinando na neve... Tu gostas também de imaginar trombas de elefante passando pela grade, assim (reproduzo).

Ele tem o sorriso contido no rosto, parecendo gostar, e busca ativamente dar continuidade a essa interação.

T: Agora tu estás olhando o outro plug da luz... Agora teus olhos estão seguindo um mosquito...

Ritmicamente, estamos numa dança que simula um diálogo que transcende o verbal. "Palavra, gesto do rosto, tom de voz e ação motriz se conjuntam para auspiciar um clima lúdico no encontro" (Guerra, 2014b, p. 15). Deste modo, vou tomando seus movimentos como comunicação de sua vida mental, permitindo que as palavras criem bordas, circunscrevendo as vivencias de seu self e marcando uma identidade.

Para Martins e Silva (2017) a clínica com bebês e crianças com falhas na subjetivação requer um analista mais ativo, e que conte com uma disposição especial ao enlace intersubjetivo. Em consonância com essa ideia, nessa cena procuro me fazer presente psiquicamente para $\mathrm{K}$, estando atenta a tudo que o interessa e buscando captar sua atenção. À medida que ele vai sentindo que sou uma companhia viva (Alvarez, 1994), acompanhando cada movimento seu, compartilhando afetos e percepções, ele começa a se envolver nesse jogo intersubjetivo. Ao atrair intencionalmente minha atenção através do olhar, ingressamos no que Guerra (2009) chama de vocativos atencionais do bebê.

Eu me esforço para co-criar o sentido de nossas vivências, observando toda oportunidade para tecer comentários sobre aquilo que o atrai no universo que nos cerca. Pensamos que essa atitude retrata uma forma de se fazer uma presença simbolizante, sugerida por Guerra $(2013,2017)$. É verdadeiramente uma dança da subjetivação: palavra, ritmo, apropriação dos objetos do mundo se entrelaçam como num jogo conjunto, o jogo de desvendar os enigmas que nos habitam (Guerra, 2013). 


\section{Musicalidade Comunicativa: A Criação de uma Linguagem Compartilhada}

R (9 anos) era um menino com grandes dificuldades para ingressar em uma conversação recíproca. Uma evolução muito significativa em seu tratamento foi quando começou a criar seus próprios códigos linguísticos na sessão. Antes disso, muitas palavras eram barulhos ou elementos acústicos concretos. Por exemplo, algumas vezes ele se assustava com ruídos do ambiente, ou não era capaz de uma discriminação auditiva coerente, sentindo-se perdido em meio às percepções sonoras, por vezes não conseguindo nem se orientar pelo que era verbalizado.

Para Françoise Dolto (2004), o que há de mais humano é o desejo de se comunicar. Porém, "mesmo quando existem palavras, sons... se estes não significam para o sujeito-criança comunicação de uma pessoa com sua pessoa, pode existir uma espécie de brecha na simbolização, capaz de resultar na esquizofrenia" (Dolto, 2004, p. 31). As palavras passam a existir assim como barulhos sem sentido, pois não narram as emoções verdadeiras e as sensações, não comunicam a vida, o amor e o ódios pertinente às relações.

Nessa mesma linha, Guerra (2013) adverte que não é qualquer palavra que representa um símbolo. Ela tem que vir como ponte de uma lembrança compartilhada. De outro modo, se trata de uma "palavra desafetizada, operatória, ou puro recrudescimento de uma vida intelectual, blindada, desprovida de afetos, tão própria de tantas patologias psíquicas" (Guerra, 2013, p. 585). Assim, se ela não está em relação à marca do encontro com o outro, não é símbolo. No caso de $R$, como as palavras de seu ambiente não teceram elos, ficaram desvinculadas de si e das sensações do mundo.

Por este motivo, a seguinte aquisição marcou um avanço importante de G. Não recordo exatamente como, mas chegou um ponto em que estabelecemos que alguns gestos iriam significar situações específicas. Creio que isso se deu em razão de que, em alguns momentos, ele apenas olhava para o que queria fazer esperando que eu adivinhasse. Juntos acabamos co-criando uma linguagem comum. Resolvi registrar nossos códigos em um papel, e cada um significava algo diferente, como: brincar na casinha, brincar com massinha, ir embora ou fazer qualquer coisa (ele inventou também uma palavra para significar isso).

Já vimos que a protoconversação (segundo indicador de intersubjetividade) é o modo como os bebês inauguram suas comunicações verbais, produzindo e imitando alguns sons e observando o efeito que produzem no seu interlocutor. Isso permite sustentar um diálogo imaginário com o bebê e aumentar a qualidade das trocas afetivas. Assim, se estabelece uma conversação em que o prazer sonoro e das trocas desse jogo tem precedência sobre os 
significados da língua, assemelhando-se a uma composição musical a dois (Guerra, 2014a, 2014c). Penso que esses códigos cunhados por mim e por R na sessão se referem a uma possiblidade de viver ali na transferência a co-criação e o compartilhamento dessa linguagem única da infância, tal como são as protoconversações na relação mãebebê.

A partir da possibilidade de juntos atribuirmos significado, fazermos ligações com esses gestos e inventar palavras, expandiu-se em sua mente o desenvolvimento de capacidades mais simbólicas, que pode facilitar a aquisição da linguagem verbal propriamente dita (último indicador de intersubjetividade). Mas, para isso, o prazer dessa gestualidade criativa e comunicativa teve precedência sobre o sentido da linguagem falada. Através de um compartilhar emocional guiado por mímicas, gestos e sons foi se operando as marcas da simbolização em presença, que por sua vez acedeu à "elaboração da ausência e o acesso à representação do objeto", dando lugar nesse interjogo ao domínio da palavra (Guerra, 2014a, p. 138).

\section{Objeto Tutor: Pedacinhos da Terapeuta a Construir um Espaço Transicional}

Rapidamente $L$ ( 4 anos) se vinculou a mim, demonstrando gostar de estar ali, embora testasse bastante os limites na sessão, por exemplo: de súbito poderia querer abrir a porta do consultório que ficava chaveada, forçando a dobradiça insistentemente. Caso as pessoas não atendessem prontamente seu desejo, ficava a mercê de seus impulsos agressivos, sem condições emocionais de estabelecer um diálogo.

Já vimos que o olhar e a expressão do adulto cuidador são parte da função de espelho, o qual será como um farol, sustentando os movimentos da criança pelo espaço. Guerra entende que, quando o rosto do outro não faz essa função de suporte e de confiança, observamos crianças com um nível maior de impulsividade, as quais não parecem capaz de mensurar o modo como podem se lançar em uma experiência nova. "Parece que se auto sustentam na intensidade sensorial e muscular da experiência. Transformariam incerteza em intensidade, sem possibilidade de metabolização psíquica" (Guerra, $2014 b$, p. 413). Esse parecia ser o caso de L. Não era possível observar nele esse olhar referencial (sexto indicador de intersubjetividade), buscando aprovação ou orientação no rosto do adulto cuidador.

Ao término das sessões algo que fui percebendo que evitava os episódios de desmantelamento do paciente era oferecer um pedaço de massinha de modelar. Essa estratégia foi co-criada por nós dois. De início, L sempre queria levar consigo algum brinquedo. Ele pegava 
aleatoriamente um, depois outro, e eu não estava convencida em deixá-lo levar materiais de uso comum do consultório, sem ter vivido com ele algum significado. Especialmente porque não parecia ser 0 brinquedo em si seu objetivo, mas carregar um objeto de nosso espaço compartilhado. Até que um dia ele pegou a massinha de modelar e achei que aquele elemento amorfo poderia ser interessante, bastante propício a ser símbolo do que pretendia construir com ele ali.

A massinha de modelar se presta bem para congregar uma experiência de transmodalidade, pela possibilidade de integração das sensorialidades (experiência que congrega o aspecto visual, tátil, olfativo). Ao permitir diferentes configurações e suportar todo tipo de pressão, indica a possiblidade de permanência e de transformação de algo: pode mudar sem deixar de ser o que é, metáfora da maleabilidade psíquica. Para Guerra (2014a), a criação de um espaço potencial depende dessa maleabilidade psíquica e gestual.

Guerra (2009, p. 11) já dizia que "a descontinuidade é maturativa somente sobre um fundo de permanência". Assim, por muitas semanas, na hora de ir embora, ao sinal de que L precisava de algo para servir como continuidade do que vivíamos ali, eu recorria à massinha, ou ele mesmo já se dirigia para buscar um pedaço dela. Isso inclusive foi verbalizado para o paciente: "Tu queres levar um pedacinho do nosso espaço contigo?", e ele confirmava com a cabeça que sim. O menino foi juntando vários desses pedaços e a mãe intuitivamente os guardou dentro de um pote de plástico transparente, o qual L carregava por onde ia, tal como um amuleto, principalmente na escola.

O adulto que se ocupa da criança pode responder de duas formas àquilo que capta sua atenção: com uma atenção conjunta mais operatória, a qual diz respeito a situações em que somente confirma que percebeu o que está no seu centro de interesse, mas não introduz nenhuma fantasmática na cena. Ou, de modo mais narrativo, acrescentando elementos a essa experiência, de maneira rítmica e lúdica, dando consistência a esse campo intersubjetivo, criando um espaço transicional (Guerra, 2014b). Esses objetos vão assim sendo envelopados por comentários e histórias que se conta a seu respeito, impregnando-os de significados afetivos. Desse modo, é possível que a mãe ou cuidador se retire da cena, deixando o bebê envolvido em continuidade lúdica com esse artefato. Na ausência da mãe (nesse caso da terapeuta), a criança segue o jogo, mantendo viva a interação oferecida quando esteve na presença do brinquedo (atenção conjunta/objeto tutor, sétimo indicador de intersubjetividade).

Guerra (2009) ressalta, contudo, que esses objetos tão significativos, representantes das experiências intersubjetivas do bebê com seus cuidadores, não são a mesma coisa que os objetos transicionais. Ele 
os denomina objetos tutores. Isso porque os objetos transicionais são fixos e eleitos pela criança, enquanto os objetos tutores são frutos de um encontro prazeroso, e se prestam a cuidar da criança por um período temporário. Esse arsenal teórico sobre os objetos tutores permitiu iluminar a mente da terapeuta para o manejo das situações desafiadoras mobilizadas pela sintomática do paciente, sendo um recurso que costurou e criou um suporte para sustentar o vazio intermitente em que o paciente se sentia cair a cada mudança marcada pelo ritmo presença-ausência.

\section{Considerações Finais}

Neste artigo, procuramos sustentar que o analista conhecer e ter em mente os princípios da intersubjetividade, bem como os seus indicadores, se constitui em um recurso teórico e técnico que pode iluminar situações potencialmente propícias para fazer emergir a subjetividade do pequeno paciente, especialmente daquele que encontra falhas nesse processo. Nas cenas clínicas escolhidas, podese observar que, norteada pelos indicadores de intersubjetividade, a analista pode tanto estabelecer um caminho para compreender alguns funcionamentos psíquicos dos pacientes e entraves no processo de subjetivação, como articular as oportunidades de abertura surgidas no aqui-agora com o paciente, para construir situações e jogos rítmicos, típico dos primeiros anos de vida, os quais se entendem como estruturantes do psiquismo.

Ou seja, com K (vinheta 1), partindo da análise do olhar do menino foi possível perceber a fragilidade de sua mente, que funcionava de modo raso, bidimensional e, usando o caminho da narrativa e da imitação de seus gestos, inserida dentro dos indicadores de intersubjetividade, estabelecer comunicações arcaicas e profundas, em que o paciente se sentiu envolvido, acompanhado e compreendido. A sensação de "estar com" um paciente que parece viver perdido em um deserto como era o caso de K é um fato clínico de extrema relevância (Alvarez, 1994).

Com R ( vinheta 2), da simples expectativa do paciente de estabelecer com a terapeuta uma atenção conjunta - levando-a a ler de modo onipotente suas intenções, o que evidenciava uma forma ainda pouco desenvolvida emocionalmente de se relacionar para um menino de 9 anos - os indicadores de intersubjetividade serviram mais uma vez como guia, permitindo a analista encontrar o recurso de co-criar uma linguagem própria entre ambos, tal como a protoconversação mãebebê. Tal intervenção nos parece ter sido fundamental para 0 desenvolvimento posterior de capacidades mais simbólicas e comunicativas do menino, o qual não era antes capaz de encontrar significado nos significantes da língua de seus semelhantes. 
E, por fim, com L (vinheta 3) o conhecimento dos entraves no processo rítmico de subjetivação, acionados pelo descompasso na oscilação dos eixos presença-ausência, e a noção dos objetos tutores inspirou a uma saída criativa, levando à construção de pontes entre o paciente e a terapeuta, ampliando as condições de internalização, introjeção, permanência do objeto e consequentemente de melhoria das relações de um menino que sentia-se ruir a cada descontinuidade nos encontros com o outro.

Assim, o olhar, o espelhamento, a protoconversação, o diálogo tônico, o objeto tutor não são lidos como meros conceitos teóricos observáveis, mas tornam-se a própria ferramenta do analista, na medida em que ele é capaz de uma maleabilidade lúdica para transformar essa bagagem em recursos técnicos, que se constituem em bases dos processos de simbolização. Entendendo especialmente que é "a ritmicidade do encontro com o outro (intersubjetividade) um dos fatores que possibilita, junto aos recursos próprios, a vivência de integração do self (subjetivação) e o acesso a intersubjetividade" (Guerra, 2017, p. 14).

Para finalizar, gostaríamos de deixar claro que esse estudo não tem como propósito comprovar a eficácia de tal abordagem, mas sim compartilhar um modo de intervir que, no atual contexto histórico, tem se mostrado para nós bastante potente. Entendemos que essa abordagem retrata uma postura clínica de "esperança", essencial para aqueles que trabalham com bebês ou crianças pequenas com graves problemas de subjetivação (Martins \& Silva, 2017), uma vez que permite uma saída ética mais positiva e cautelosa diante da dificuldade de encontrar limites para o TEA. Sua potência está em iluminar leituras e caminhos clínicos, abrindo passagem para outros possíveis entendimentos, intervenções e prognósticos para aqueles pacientes com falhas na simbolização, na interação e na comunicação.

Convém ressaltar que, nessa perspectiva teórica, a subjetividade do analista também está em jogo no tratamento. Trata-se, portanto, de uma forma de atuar em que precisa haver um investimento afetivo e mental constante. É necessário se deixar tocar e sentir, envolver-se pela situação, bem como é imprescindível um genuíno interesse, maleabilidade e disponibilidade lúdica como recursos internos do analista na busca de oportunidades para espelhar, traduzir, brincar e transformar as situações clínicas que se apresentam (Guerra, 2015, 2017).

A presença sensível do analista (Kupermann, 2008) é fundamental para que circulem no setting as comunicações não verbais. Além dessa disposição afetiva particular, evidentemente, o conhecimento teórico é indispensável. Esse conjunto permitirá ao terapeuta reconhecer na sessão quando é mais apropriada uma abordagem narrativa ou de imitação intensificada das emoções da criança, ou a 
inserção de jogos rítmicos envolvendo suspense e prazer. Essas estratégias facilitam engajar o pequeno paciente em comportamentos intersubjetivos, que por sua vez o ajudam a apropriar-se de si, de seus estados mentais e diferenciar-se dos outros. Tais interações serão proveitosas para colocar em marcha processos constitutivos, que promovem um funcionamento mais simbólico (Muratori, 2008).

Por fim, salientamos que essa se trata de uma clínica bastante artesanal. E, como toda arte, o processo tem um caráter criativo e singular. Logo, se configura como um trabalho aberto, inventivo, espontâneo e fecundo, longe de corresponder a uma espécie de protocolo de intervenções. Por este motivo, exige perspicácia, flexibilidade e uma dose de arte para ser realmente um tratamento co-criado entre o analista, o paciente e sua família. "Se entendermos a subjetivação como um processo aberto, de tornar-se sujeito, sabemos que é interminável e que é também uma encruzilhada repleta de incertezas, mistérios, um pouco de casualidade, muita paciência e criação" (Guerra, 2017, p. 8).

Assim, como fios tecendo representações, ritmo, palavra, jogo e o investimento do outro vão costurando essa trama. O ritmo, permeado pela repetição prazerosa do encontro, acompanhado de palavras que fazem elos, entrelaçados pelo olhar, atenção e pela atitude lúdica do terapeuta, são fios a compor nessa dança a textura da vida psíquica (Guerra, 2013).

\section{Referências}

Frances, A. (2013, May 25). Two Fatal Technical Flaws in the DSM-5 Definition of Autism. Huffpost. Recuperado de http: // www. huffingtonpost.com/allen-frances/two-fataltechnical-flaws_b_3337009.html

Alvarez, A. (1994). Companhia Viva. Porto Alegre: Artes Médicas.

Dolto, F. (2004). A imagem inconsciente do corpo. São Paulo: Perspectiva.

Ferrari, H. (2011). Qué nos enseña Freud acerca del relato clínico psicanalótico. In Relatos de Lá Clínica: XXXIII Simpósio Anual da Associação Psicanalítica de Buenos Aires (pp. 121-127). Buenos Aires, Argentina.

Figueiredo, A. C. (2004). A construção do caso clínico: uma contribuição da psicanálise à psicopatologia e à saúde mental. Revista Latino Americana de Psicopatologia Fundamental, 7(1), 75-86. doi: 10.1590/1415-47142004001006

Fraiberg, S., Adelson, E., \& Shapiro, V. (1994). Fantasmas no quarto do bebê - uma abordagem psicanalítica dos problemas que entravam a relação mãe-bebê. Revista do CEAPIA, 7(7), 12-34. (Original publicado em 1975) 
Golse, B. (2013). Mon combat pour les efantautistes. Paris: Editora Odile Jacob.

Guerra, V. (2009). Indicadores de intersubjetividade (0-2 años) em el desarollo de la autonomia del bebe. In S. Mara (Org.), Aportes para la elaboración de propuestas educativas - Primera Infancia: la etapa educativa de mayor relevancia. Montevideo, Uruguay: Ministério de Educación y Cultura.

Guerra, V. (2013). Palavra, ritmo e jogo: fios que dançam no processo de simbolização. Revista de Psicanálise da Sociedade Psicanalítica de Porto Alegre, 20(3), 583- 604. Recuperado de http://revista.sppa.org.br/index. php/RPdaSPPA/article/view/11 0

Guerra, V. (2014a). Indicadores de intersubjetividad 0-12 Meses: Del encuentro de miradas al placer de jugar juntos (Parte I). Revista da Sociedade Brasileira de Psicanálise de Porto Alegre, 16(1), 209-235. Recuperado de http://sbpdepa.org.br/site/wpcontent/uploads/2017/03/Indicadores-de-Intersubjetividad-0-

12-Meses-del-encuentro-de-miradas-al.pdf

Guerra, V. (2014b). Indicadores de intersubjetividad 0-12 Meses: del encuentro de miradas al placer de jugar juntos (Parte II). Revista da Sociedade Brasileira de Psicanálise de Porto Alegre, 16(2), p. 411-435. Recuperado de http://sbpdepa.org.br/site/wpcontent/uploads/2017/03/Indicadores-de-Intersubjetividad-012-Meses-del-encuentro-de-miradas-al-1.pdf

Guerra, V. (2014c). Indicadores de intersubjetividad 0-12 Meses. Del encuentro de miradas al placer de jugar juntos [Vídeo documental]. Associação Psicanalítica do Uruguai: Comitê Outreach de la I.P.A.

Guerra, V. (2015). La escucha sensorial e estética del analista: desde J. Keats à clínica infantil. Revista da Sociedade Brasileira de Psicanálise de São Paulo, 17(2), 154-177. Recuperado de https://docplayer.com. br/24508249-V-17-n-2-2015-

psicanalise-revista-da-sociedade-brasileira-de-psicanalise-deporto-alegre. html

Guerra, V. (2016). Formas de (des)subjetivação infantil em tempos de aceleração: os transtornos de subjetivação arcaica. Revista de Psicanálise da Sociedade Psicanalítica de Porto Alegre, 23(1), p. 137-158. Recuperado de http://revista.sppa.org.br/index. php/RPdaSPPA/article/view/23 1

Guerra, V. (2017). O ritmo, a musicalidade comunicativa e a lei materna na artesania da subjetivação humana. Revista de Psicoterapia da Infância e Adolescência (Publicação Ceapia), 26(26), 8-21. Recuperado de http://www.bivipsi.org/wpcontent/uploads/O_Ritmo_a_musicalidade_comunicativa.pdf 
Jerusalinky, A. (2015). Dossiê Autismo. São Paulo: Instituto Langage. Kupermann, D. (2008). Presença sensível: a experiência da transferência em Freud, Ferenczi e Winnicott. Jornal de Psicanálise, 41(75), 75-96. Recuperado de http://pepsic. bvsalud.org/pdf/jp/v41n75/v41n75a06.pdf

Kupfer, M. C. M. (2014). O impacto do autismo no mundo contemporâneo. In M. Kamer, R. M. Mariotto, \& R. Voltoline (Orgs.), Por uma nova psicopatologia da infância e adolescência (pp. 105-110). São Paulo: Escuta.

Mahler, M. (1982). O processo de separação-individuação. Porto Alegre: Artes Médicas.

Marcelli, D. (2000). La surprisechatouille de I'ame. Paris: Albin Michel.

Martins, P. G., \& Silva, M. R. (2017). O psicoterapeuta na clínica de bebês com transtornos de subjetivação. Estilos da Clínica, 22(3), 488-506. doi: 10.11606/issn.1981-1624.v22i3p1-19

Martins, P. G., \& Giaretta, V. (2017). A função subjetivante do ritmo em um contexto de atendimento psicanalítico. Revista Brasileira de Psicoterapia, 19(2), 59-71. Recuperado de http: //rbp.celg.org.br/detalhe_artigo. asp?id=231

Muratori, F. (2008). El autismo como efecto de un transtorno de la intersubjetividade primaria (I Parte). Revista de Psicopatología y salud mental del niño y del adolescente, 12, 39-49

Stern, D. (1980). Bebê-Mãe: primeira relação humana. Lisboa: Editora Moraes.

Stern, D. (2004). O momento presente na psicoterapia e na vida cotidiana. Rio de Janeiro: Record.

\section{Endereço para correspondência \\ Vanessa Giaretta}

Rua Coronel José Rodrigues Sobral, 421/27, CEP 91510-000, Porto Alegre - RS, Brasil

Endereço eletrônico: gianessa84@yahoo.com.br

\section{Milena da Rosa Silva}

Rua Ramiro Barcellos, 2600, Santa Cecília, CEP 90035-003, Porto Alegre - RS, Brasil

Endereço eletrônico: milenarsilva@hotmail.com

Recebido em: 19/09/2018

Reformulado em: 11/02/2019

Aceito em: 15/03/2019

\section{Notas}

* Psicóloga, especialista em Psicoterapia Psicanalítica da Infância e Adolescência pelo Centro de Estudos, Atendimento e Pesquisa da Infância e Adolescência (CEAPIA) e Mestre em Psicanálise: Clínica e Cultura, pela Universidade Federal do Rio Grande do Sul. 
** Psicóloga, Doutora em Psicologia pela UFRGS, Pesquisadora e Professora do Programa de Pós-Graduação em Psicanálise: Clínica e Cultura, da Universidade Federal do Rio Grande do Sul.

${ }^{1}$ Nessa sessão, usaremos a escrita em primeira pessoa do singular na maior parte do texto, pois se tratam de vinhetas de atendimentos clínicos realizadas pela primeira autora do presente artigo.

Este artigo de revista Estudos e Pesquisas em Psicologia é licenciado sob uma Licença Creative Commons Atribuição-Não Comercial 3.0 Não Adaptada. 